\title{
An Exploratory Study of the Research Mentor Experience in a Novel Under- graduate Aerospace Engineering Course
}

\section{Irene B Mena, Pennsylvania State University, University Park}

Irene B. Mena has a B.S. and M.S. in Industrial Engineering, and a Ph.D. in Engineering Education. Her research interests include first-year engineering and graduate student professional development.

\section{Dr. Sven Schmitz, Pennsylvania State University, University Park}

Dr. Sven Schmitz joined the faculty of Aerospace Engineering at Penn State University in 2010. He received a diploma degree in Aerospace Engineering from RWTH Aachen (Germany) in 2002 and a Ph.D. in Mechanical and Aeronautical Engineering from the University of California Davis in 2006. Dr. Schmitz spent four years as a post-doctoral researcher and project scientist at Davis before coming to Penn State. $\mathrm{He}$ is an expert in rotary wing aerodynamics with an emphasis on vortical flows. His research program embraces the areas of wind turbine aerodynamics and rotorcraft aeromechanics. Current activities include wind farm wake modeling, icing on wind turbines, rotor hub flows, and rotor active control. 


\title{
An Exploratory Study of the Research Mentor Experience in a Novel Undergraduate Aerospace Engineering Course
}

\begin{abstract}
This study looks at the experiences of seven graduate/postdoctoral research mentors in a novel aerospace engineering course that introduced undergraduate students to research at a midAtlantic research University. In this course, groups of (typically) three undergraduate students were mentored by one graduate student. The undergraduate students worked with and were led by these research mentors in various aerospace engineering research projects. In many cases, the undergraduate students were working on a project related to the research mentors' theses or research work. Previous studies looking at the undergraduate research experience do so from the undergraduate students' perspectives; this paper focuses on this experience from the research mentors' perspectives. In this paper, the experiences of seven research mentors who were involved with the course in the fall 2011 and spring 2012 semesters are described. The paper answers the following research questions: (1) What benefits result from being a research mentor? and (2) In what ways does being a research mentor prepare graduate students for their future careers?

Data were collected via individual interviews with the research mentors at the end of each semester. Using situated learning as the theoretical framework, the data were analyzed to determine themes that characterized the research mentor experience. The theory of situated learning was used to identify and inform the ways in which being research mentors can prepare the mentors for their future careers, specifically in terms of how they are prepared to become members of the communities of practice they aspire to join. The benefits for research mentors were classified as follows: (1) benefits related to preparation for their future careers, such as strengthening their technical skills and content knowledge, and developing and improving various professional skills, and (2) benefits related to their current positions as students/postdoctoral scholars, such as receiving help with their theses or research projects.

This study is part of a longer-term study to determine the effectiveness of this aerospace engineering course, both in terms of the undergraduate students' learning experiences, and in terms of the graduate students' professional development. The results shared in this paper can be useful to universities, departments, and faculty members who: (1) are interested in graduate student professional development, and (2) would like to learn about a novel way to involve graduate students in undergraduate courses.
\end{abstract}

\section{Introduction}

Undergraduate research experiences come in a variety of forms, including summer research, intern or co-op programs with research as the principal component, and research-based junior and senior theses ${ }^{1}$. Regardless of the type of undergraduate research that is undertaken, these experiences have been shown to be beneficial to undergraduate students in different ways. For example, participating in undergraduate research can improve students' research skills, including collecting and interpreting data and communicating findings from research studies ${ }^{2}$.

Participating in research has also been found to increase students' confidence in their abilities 
and to increase awareness of career options and the nature of graduate school ${ }^{1}$. Another benefit of undergraduate research experiences is an increased or continued interest in postgraduate education $^{3,4}$.

Studies have looked at various aspects of the undergraduate research experience, including: undergraduate students' preconceptions of research ${ }^{5}$, faculty and student ratings of students' research skills $^{2,6}$, and the effect of undergraduate research on persistence ${ }^{7}$, among others. Some studies have looked at undergraduate research from the mentors' perspectives, focusing on the gains experienced by graduate and postdoctoral mentors ${ }^{8,9}$. These gains, as outlined by Dolan and Johnson ${ }^{8}$, fall under the following categories: instrumental (such as improved research productivity), socio-emotional (such as greater confidence), interpersonal (such as better communication skills), professional, and cognitive.

The purpose of this study is to continue to look at the undergraduate research experience from the mentors' perspectives, specifically in terms of if/how being mentors would be a professional development opportunity for them. Research in this area will be useful as we continue to understand the benefits of undergraduate research, and as we attempt to find areas for improvement. In addition to contributing to the literature on undergraduate research experiences, this study will contribute to the literature on graduate student professional development. If being research mentors helps effectively prepare graduate students for their future careers, then it may become an experience that they should be encouraged to pursue as part of their graduate work.

\section{Research questions}

In this paper, we attempt to answer the following research questions: (1) What benefits result from being a research mentor? and (2) In what ways does being a research mentor prepare graduate students for their future careers?

\section{Theoretical framework}

This study was guided by the literature on situated learning. Situated learning is a theory that "emphasizes and promotes real and authentic learning" (p.3) ${ }^{10}$. This type of learning occurs in context - learners are engaged in authentic activities, as part of a community of practice.

Authentic activities refer to the "coherent, meaningful, and purposeful activities" (p.34) ${ }^{11}$ that are shared by members of a community of practice and in fact characterize that community. Participating in authentic activities enables learners to understand experts' points of view, "shapes or hones [learners'] tools," and provides them with experience (p.36) ${ }^{11}$.

As a social theory of learning, situated learning suggests that learning is concerned with the "whole person" - both in terms of the activities the person engages in, and also in terms of the communities the person belongs to or will belong to (p.53) ${ }^{12}$. Lave and Wenger" (p.53) explain that activities exist as part of bigger "systems of relations" that emerge from communities, and activities gain their meaning as a result of these systems. The communities, in turn, influence and are influenced by the person; it is therefore suggested that learning implies a change in the learner ${ }^{12}$. 
This study has the goal of understanding the ways in which being research mentors for undergraduate students can prepare the mentors for their future careers. That is, it seeks to understand the ways in which being a mentor is or could be a situated learning experience for the mentors, in terms of how they are prepared to become members of the communities of practice they aspire to join.

\section{Context of the study}

This paper is part of a longer-term study looking at the development of a novel, three-credit, 400level undergraduate course in the Department of Aerospace Engineering at a large, public, midAtlantic University ${ }^{20}$. The goal of this course is to have undergraduate students work with graduate students on research projects. Groups of (typically) three undergraduates would be mentored by one graduate student. In many cases, the graduate students would be involved with this course as volunteers, because the projects would be somehow related to their own research projects and theses; in other cases, graduate students would receive course credit. Different faculty members, in addition to the course faculty, also served as mentors for the groups. So, one group of undergraduate students would be closely mentored by one graduate student and supervised by the course faculty. They would also be (less frequently) mentored by another faculty member who was involved with or in charge of the particular project they were working on. The figure below illustrates the supervisory structure for the course. I1 and I2 represent the two course instructors. Next in this structure is an experienced doctoral student who served as an official teaching assistant for the course. The circles with numbers represent the different mentors, each one mentoring groups of typically three undergraduate students. The faculty who occasionally provided additional mentoring for the groups are not represented in this figure.

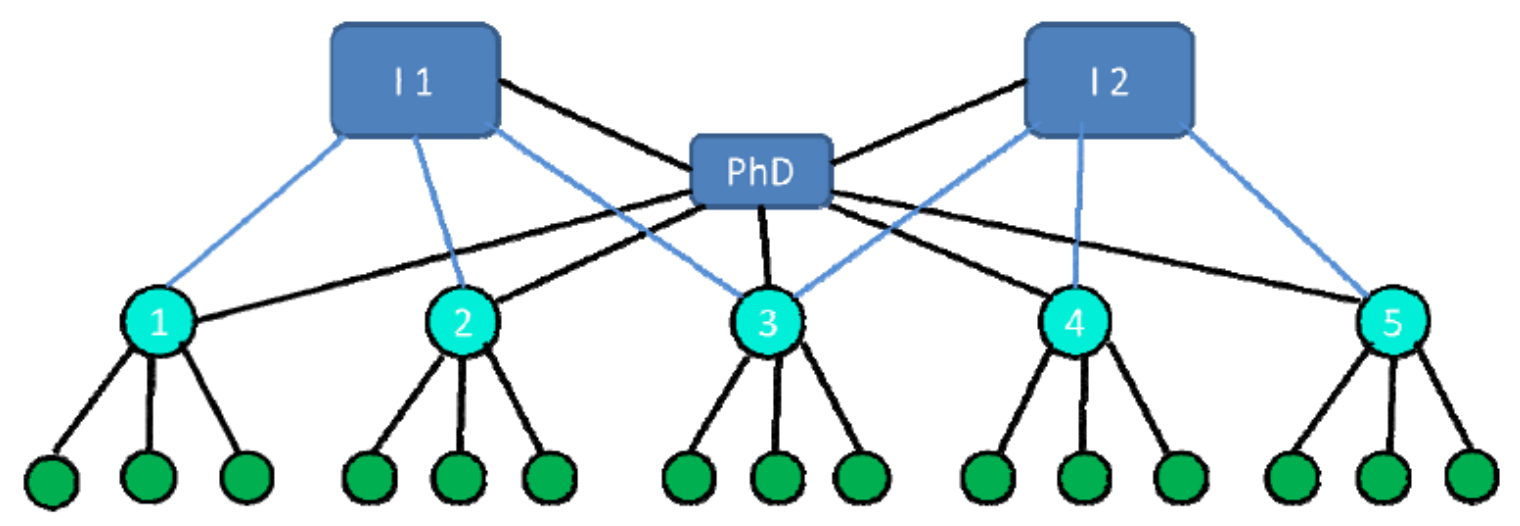

Figure 1: Supervisory structure

The goal of our longer-term study is to determine the effectiveness of this course, both in terms of the undergraduate students' learning experiences, and in terms of the graduate students' professional development. To do this, we have been collecting quantitative and qualitative data from the undergraduate students taking the course, the (typically) graduate students working as mentors, and members of the faculty who mentored some of the groups. This paper focuses on the mentors' experience in this course, based on the experiences described by the individuals who were mentors the first two semesters of the study. 


\section{Data gathering methods}

This paper shares some of the data collected from the first year of the study. This first year of the study, data was collected for the fall 2011 and spring 2012 sections of the course. The fall 2011 section of the course was titled "Experimental Methods and Projects," and the spring 2012 section was titled "Wind Energy Engineering." Both courses consisted of undergraduates working on research projects with graduate students, as described above, but the spring section of the course had a greater focus on wind energy.

Each semester, pre and post surveys were administered to the undergraduate students to learn about how the course teaching methods, mentors, and research/project work were helpful to their learning. Several class and lab sessions, as well as some individual group meetings, were observed by an engineering education researcher. At the end of the semester, undergraduate students participated in a focus group to talk about the course. The mentors and faculty participated in one 20-30 minute individual interview. In this paper, we use data from the interviews with the mentors to describe their experience with the course.

\section{Data analysis and interpretation}

The first step in the analysis of the interview data was to carefully read all interview transcripts, as suggested by Creswell ${ }^{13}$. This first step started to reveal some of the main themes in the interviews. Each interview transcript was then re-read with the purpose of assigning codes, or "tags or labels" that assign "units of meaning" (p.56) ${ }^{14}$ to the data. The codes were revised and again applied to the data. This last step resulted in themes that described the mentors' experiences in the course. The data analysis process took place within NVivo.

\section{Results}

A total of seven mentors, all male, were interviewed in the 2011-2012 school year. Four out of the seven were mentors for both the fall 2011 and spring 2012 sections of the course. Three of these were interviewed twice - once each semester. The fourth only participated in the spring 2012 interview. The remaining three out of the seven were mentors only in the fall 2011 semester.

Three mentors were in the Department of Aerospace Engineering's Master's program, while two were in the $\mathrm{PhD}$ program. While the original goal of the class was to have all mentors be graduate students, this was not the case for the first two semesters of the course. One of the mentors was a postdoctoral scholar, and another was a very advanced undergraduate student - a senior who had previously worked with one of the faculty members in charge of the course. This undergraduate student was a nontraditional student, so he was a few years older and more experienced than the undergraduate students he mentored. Four out of the seven mentors were interested in careers in industry, one was interested in an academic career, and two were not sure. These mentors mentioned various factors that motivated them to be involved with this course, including: getting help on their research projects/theses, learning more about the topics and 
research areas covered in the course, and being invited or asked to participate by the course faculty and/or their advisors.

Before answering the research questions, a brief description of the mentors' responsibilities may be helpful to better understand their roles as research mentors. For the first few weeks of the semester, the course followed a regular course format. Students would meet with the faculty in a classroom setting to learn about different concepts. Students were then divided into groups and assigned research projects. They worked on these research projects until the end of the semester, when they presented their results. Each group was led by a mentor. The mentors' main responsibility was to oversee the research project. One mentor described his role as follows:

"Basically, I guess it would be mostly organizational and trying to set out a plan of action of how we were going to accomplish our goals for the semester. And immediately, we tried to split up the group as far as what needed to get done and just assigning tasks to each [person], and we set up group meetings and figuring out when everybody was available. And then, I guess, just kind of giving direction to what we were doing, too, because it was my research project."

The mentors met regularly with their groups and with the course faculty. The groups also met with other faculty members who were involved with and/or were supervising their projects. In addition, during the fall 2011 section of the course, the course faculty organized meetings with just the mentors. In these meetings, the mentors (without the undergraduate students) met together with the faculty, provided project updates, and received instructions.

The benefits received as a result of participating in this course, as explained by the mentors, fell under two main categories: benefits as related to preparation for their future careers, and benefits as related to their current positions as students and postdoc. Each of these categories is explained in more detail below.

\section{$\underline{\text { Benefits as related to preparation for their future careers }}$}

The mentors talked about how the experience of being a mentor was preparing them for their future careers in industry or academia. As a result of being mentors, they were developing a wide variety of professional skills as well as strengthening their technical skills and content knowledge.

The mentors were most emphatic about how being involved with this course helped them develop the necessary skills for successfully managing and working with people. For example:

"I got some experience with dealing with a group and trying to manage everybody's time and experience levels and stuff like that, so that was helpful."

"I think that just through working in a group and managing a group...it kind of helps you understand what it means to be looking over different people's shoulders and making sure that they're getting the work done that they need to get done and really providing the support that you can to make sure that they can get it done on time and make sure that 
they are understanding what's going on. I think that will help me in the future if I move into a management position."

Perhaps the mentors felt so strongly about this skill because they expect that teamwork and being team leaders will be a certain part of their future careers. One mentor described it as follows:

"I think in any career you need leadership and [the ability] to work with a team. That's the one thing they tell me - that you need to be able to work with a team, and that's going to go anywhere. In engineering, that's kind of the standard that you're going to have. So you really need to be able to work with a team and understand what it takes to be a team leader..."

The mentors stated that the course helped them develop project management skills: they had to determine goals, schedule, and plan to meet the established goals. Two mentors described it as follows:

“...this whole class helps you set a plan up and try and reach that plan. It definitely helps you balance where you want to be...So you got to keep constantly updating your goals and figuring what to do..."

"Having - being able to manage people, a schedule - hopefully stay on schedule - that's all a value."

One mentor talked about how learning these project management skills was one reason he would recommend this experience to other graduate students:

"I recommend all grad students [participate in this course]. It really helps. If you can run a project and be with other people and interact and stuff and you can still manage, I think it's a good experience."

Leadership was another skill mentioned by the mentors. They expressed that participating in this course helped them get leadership experience. To a lesser degree, mentors mentioned improving their teaching skills. It may be that improvement in teaching skills was not frequently mentioned because only one mentor was interested in an academic position. The majority of the mentors were interested in careers in industry, and may have been thinking about the skills that they would more likely be using in that setting.

Another way this experience helped prepare the mentors for their future careers was by improving their technical skills and content knowledge. They got experience setting up experiments and learned about computer codes and electrical systems. They said:

"You definitely learn a lot. You're forced to, due to your project. We do weekly progress reports. They're about a page each week, and that forces you to sit down and realize what you're learning and whatnot. So it's just solidifying what you know. I think that's great." 
"It's been really good for me because it's made me go back and relearn those things and even dive deeper into some of the theory and some of the codes that we've been using and really try to understand where the formulas and equations come from and how they really applied.."

Being responsible for a research project and a group of students meant that the mentors had to make sure they were familiar with the tasks and the content, which is one of the reasons their technical skills and content knowledge improved:

“...I had to make sure I knew more than [the undergraduate students] just to be able to help them with all their stuff. So they may only have [been assigned] an isolated area [of the project], but I had to know it all...So I felt that was the biggest challenge - was just staying above them and making sure I had an answer for them."

\section{$\underline{\text { Benefits as related to their current positions }}$}

The mentors also talked about how the experience of being a mentor was benefiting them in their current roles as students and postdoc. First, as mentioned above, their technical skills and content knowledge improved. This would be beneficial to the mentors in future courses and in their theses and research projects. Second, they talked about how working in this course was very enjoyable to them, specifically in three ways: (1) the mentors enjoyed the hands-on aspect of the projects, (2) they enjoyed realizing that they accomplished something, and (3) they enjoyed interacting with the undergraduate students. These reasons are best described by these mentors:

"...it is nice to work with your hands and actually accomplish something - be able to look up and see [what you did] and say, 'I did that."'

"I really enjoy working with the students... all this pain they go through all semester of us trying to tell them to write things, to do things, design it this way... They finally put it together; they assembled it correctly. That's the fun part, as they really see, 'You know, this actually really came together pretty well.' That's really the fun part."

Third, mentors who were volunteers for this course (instead of participating for credit) received help on their research projects or theses. They considered this to be a great benefit of participating in this course. They said:

"I got so much done this semester that alone, I would not have been able to do."

“...I got a lot of help on my research project. I had nothing when I started, and now I have something... So that was helpful. And I mean it's always good to have other people's input on things. Even if they weren't necessarily coming up with great theories, it's always better to have somebody else thinking about things, too." 


\section{Discussion}

The mentors described the benefits that result from mentoring undergraduate students in an aerospace engineering research projects course. These benefits were classified as related to their future careers and as related to their current positions as students and postdoc. Many of these benefits align with the gains described in the studies by Dolan and Johnson ${ }^{8}$ and Reddick, et al. ${ }^{9}$ : the experience increased mentors' research productivity, helped them develop and improve different skills, increased their understanding of the content, and provided them with what they considered to be an enjoyable experience.

One of the goals of this study was to learn the ways in which being a mentor could prepare them for their future careers. The study sought to learn the ways in which this experience was or could be preparing the mentors to become members of the communities of practice they aspire to join. The results indicate that this can be considered a situated learning experience for the mentors and is in fact preparing them for their communities of practice. These mentors aspired to either go into industry or academia, so their future communities of practice would be the community of aerospace engineering faculty, or the community of aerospace engineers working in industry.

The first way in which this was a situated learning experience for the mentors was that they were exposed to authentic activities ${ }^{11}$ of the communities of practice. These include:

- They had to work on and oversee a project.

- They had to work with and supervise others.

- They had to train, teach, and mentor.

For mentors going into industry, the above activities expose them to and prepare them for some of their future tasks. The activities listed above can be considered authentic activities of that community. Engineers are often called to work on projects and in teams, and even occasionally to train others ${ }^{15}$. Similarly, members of academia are expected to conduct research, teach, and work in teams ${ }^{16}$. Therefore, by participating in this course, mentors going into academia are also introduced to some of the authentic activities characteristic of that community. According to the mentors, they frequently worked out of doors and/or in labs, so they were exposed to authentic tasks of these communities in authentic settings.

Second, the mentors developed skills that were part of their communities' repertoires. In a community of practice, members have a shared repertoire ${ }^{17}$ - a set of "tools, ways of doing things, ... actions, or concepts" (p.83) ${ }^{17}$ that characterize that community of practice. The mentors reported strengthening their content knowledge and technical skills, as well as developing their teamwork, project management, leadership, and teaching skills. These are part of the engineering repertoire: engineers should have leadership and teamwork skills ${ }^{18}$, and may also be required to use project management and teaching/training skills ${ }^{15}$. These skills are also part of the academic repertoire: members of academia should have teaching and teamwork skills $^{16}$, and surely project management skills as well, as they manage research projects in 
addition to teaching and service responsibilities. Certainly, members of both communities should also have strong content knowledge of their particular area.

The mentors' experience in this course could be considered more of a partial or introductory, rather than complete, situated learning experience. While they were exposed to the communities' authentic tasks and repertoires, the area that was somewhat lacking was interaction with established members of the community of practice. To become a member of a community, aspiring members require access to "old-timers, and other members of the community" (p.101) ${ }^{12}$. To become members of a culture, learners first observe the members of that culture and then practice their behavior ${ }^{11}$. The one mentor interested in academia had an advantage over the other mentors: he interacted regularly with the course faculty and had the opportunity to begin to see what it means to be a member of academia. The majority of mentors, however, were interested in industry, so their access to members of that community was limited. More opportunities for interacting with members of their communities would have helped the mentors better assign meaning to the authentic activities and repertoire they were exposed to, and it would have helped them understand how the activities and repertoire were distinctly used in those particular communities of practice.

\section{Conclusion}

This study looked at an aerospace engineering course in which groups of undergraduate students were mentored by one advanced undergraduate student (a senior), six graduate students, and one postdoctoral scholar in different research projects. The goal of this study was to understand the ways in which the mentors benefited from the experience and how the experience was preparing them for their future careers.

The results indicated that the mentors did in fact benefit in different ways. Furthermore, the experience was preparing them for their future careers. Through the lens of situated learning, it was determined that the experience was preparing the mentors for their future communities of practice by exposing them to the communities' authentic tasks and repertoires. Mentors interested in industry would have had a more complete situated learning experience if they had had more opportunities to interact with members of industry - the members of the community of practice they aspire to join. For the mentor interested in academia, on the other hand, this course did provide access to frequent interactions with the members of that community of practice. This mentor's situated learning experience was more complete, as he was able to observe and learn from the experts of that community.

Because mentoring the undergraduate students in a research project was beneficial to the participating mentors in terms of their learning and development, faculty who advise graduate students can consider encouraging them to pursue these types of activities. Though not all departments will have a similar course in place, faculty can consider providing opportunities within their own research projects for graduate students to mentor undergraduate students. Although graduate students are generally well prepared to conduct research, they are not as well prepared to teach ${ }^{19}$. In cases in which teaching assistantships are not available, being a research mentor can provide graduate students with some of the benefits of a teaching assistantship although it is in a research setting, they will be required to teach, train, and mentor. In addition, 
because students interested in faculty careers should be assigned "progressively responsible roles in teaching" (p.22) ${ }^{19}$, being a mentor can serve as an introduction, a first step before becoming teaching assistants and teaching their own courses.

Overall, being a mentor for this course was viewed as a beneficial experience. They were exposed to tasks they will be performing and skills they will need for their future careers. While this study looked at how these mentors were being prepared to join two communities of practice in particular, it could be argued that the skills they developed would be useful to them regardless of what careers they decide to pursue in the future.

There are a few limitations to this study. First, the number of participants is small. Only seven out of a total of eleven mentors agreed to participate in the interviews. Second, participants were self-selected, and the experiences of this self-selected group may not be representative of the mentor experience. Third, the participants in this study were mentors in a very specific context, which means the findings may not be generalizable. Finally, for this initial sample, not all mentors were graduate students, as was originally intended for this course. Because the mentors were in different stages of their education (undergraduate, graduate, and postdoctoral), there were likely differences in development and goals among the participants. These differences could lead to differences in the ways in which the role of mentor is experienced, which could again limit the generalizability of the results.

Our future work will continue to look at the mentors' experiences. As this is a multi-year study, we can expect that the additional years will in the end ensure a larger sample of mentors. As a result, future papers will have a more accurate and hopefully more generalizable description and analysis of the mentoring experience.

\section{References}

1.Russell, S. H. (2008). Undergraduate Research Opportunities: Facilitating and Encouraging the Transition from Student to Scientist. In R. Taraban \& R. L. Blanton (Eds.). Creating Effective Undergraduate Research Programs in Science. New York, NY: Teachers College Press. P.53-80.

2.Kardash, C. M. (2000). Evaluation of an Undergraduate Research Experience: Perceptions of Undergraduate Interns and Their Faculty Mentors. Journal of Educational Psychology. 92(1), 191-201.

3Lopatto, D. (2004). Survey of Undergraduate Research Experiences (SURE): First Findings. Cell Biology Education. 3, 270-277.

4.Zydney, A. L., Bennett, J. S., Shahid, A., \& Bauer, K. W. (2002). Impact of Undergraduate Research Experience in Engineering. Journal of Engineering Education. 91(2), 151-157.

5.Adedokun, O. A., \& Burgess, W. D. (2011). Uncovering Students' Preconceptions of Undergraduate Research Experiences. Journal of STEM Education. $12(5$ \& 6), 12-22.

6.Cox, M. F., \& Andiot, A. (2009). Mentor and Undergraduate Student Comparisons of Students' Research Skills. Journal of STEM Education. 10(1 \& 2), 31-39.

7.Jones, M. T., Barlow, A. E. L., \& Villarejo, M. (2010). Importance of Undergraduate Research for Minority Persistence and Achievement in Biology. The Journal of Higher Education. 81(1), 82-115.

8.Dolan, E., \& Johnson, D. (2009). Toward a Holistic View of Undergraduate Research Experiences: An Exploratory Study of Impact on Graduate/Postdoctoral Mentors. Journal of Science Education and Technology. 18, 487-500. 
9.Reddick, R. J., Griffin, K. A, Cherwitz, R. A., Cerda-Prazak, A. A., \& Bunch, N. (2012). What You Get When You Give: How Graduate Students Benefit from Serving as Mentors. Journal of Faculty Development. 26(1), 3749.

10.Altalib, H. (2002). Situated Cognition: Describing the Theory (No. IR 021877 Document ED 475 183) (ERIC document).

11.Brown, J. S., Collins, A., \& Duguid, P. (1989). Situated Cognition and the Culture of Learning. Educational Researcher, 18(1), 32-42.

12.Lave, J., \& Wenger, E. (1991). Situated Learning. New York: Cambridge University Press.

13.Creswell, J. W. (2008). Educational Research. Upper Saddle River, New Jersey: Pearson Education, Inc.

14.Miles, M. B., \& Huberman, A. M. (1994). Qualitative Data Analysis ( ${ }^{\text {nd }}$ ed): Sage Publications.

15.Jankowski, C. (2006). Engineering as a Profession: Expectations and Realities. IEEE Potentials. 25(6): 6-7, 17. 16.Austin, A. E., \& Wulff, D. H. (2004). The Challenge to Prepare the Next Generation of Faculty. In D. H. Wulff $\&$ A. E. Austin (Eds.), Paths to the Professoriate (pp. 3-16). San Francisco: Jossey-Bass.

17.Wenger, E. (1998). Communities of Practice. New York: Cambridge University Press.

18.National Academy of Engineering. (2004). The Engineer of 2020: Visions of Engineering in the New Century. Washington, DC: The National Academies Press.

19.Golde, C. M., \& Dore, T. M. (2001). At Cross Purposes: What the Experiences of Today's Doctoral Students Reveal About Doctoral Education [Electronic Version]. Retrieved November 12, 2008, from www.phd-survey.org 20. McLaughlin, D. K., Schmitz, S., \& Mena, I. B. (2013). Report on the Learning Experiences of Undergraduate Students in an Undergraduate Engineering Course Integrating Teaching and Research. Paper submitted to the American Society for Engineering Education Conference \& Exposition, Atlanta, GA, June 23-26. 